\title{
A Snapshot at the Poetry of Edward Estlin Cummings:
}

\section{A Linguistic Exploration}

\author{
Ahmed Abdel Azim ElShiekh ${ }^{1,2}$, Ala Eddin Sadeq ${ }^{1} \&$ MS Mona Ahmed Saleh ${ }^{3}$ \\ ${ }^{1}$ Zarqa University, Jordan \\ ${ }^{2}$ Alexandria University, Egypt \\ ${ }^{3}$ Bibliotheca Alexandrina, Egypt \\ Correspondence: Ahmed Abdel Azim ElShiekh, Zarqa University, Jordan. Tel: 79-595-5838. E-mail: \\ shishuj@gmail.com
}

Received: May 14, 2012

Accepted: May 29, $2012 \quad$ Online Published: August 21, 2012

doi:10.5539/ells.v2n3p102

URL: http://dx.doi.org/10.5539/ells.v2n3p102

This research is funded by the Deanship of Academic Research and Graduate Studies at Zarqa University Jordan.

\begin{abstract}
This paper deals with an exploration of the poetry world of E. E. Cummings' (Edward Estlin Cummings, October 14, 1894- September 3, 1962) from a linguistic perspective. For limitations of time and space, a couple of his representative poems are selected with the purpose of conducting a stylistic analysis of his poetry in the light of discourse analysis with particular reference to lexical and syntactic features that help make Cummings' style a peculiar example of style as deviation from the norm.
\end{abstract}

Keywords: stylistics, deviation, lexical features, grammatical features, spontaneous readers' responses, critical responses

\section{Introduction}

\subsection{Topic of the Research}

The focus of the research falls on a sample of E. E. Cummings' poetry, consisting of two poems regarded as expressive texts. According to Reiss (1976), expressive texts refer to language used in order to reflect the sender's state of mind, including his/her feelings about or attitude to a particular topic. As the sender will select those words and structures that best support his/her attitude to or emotional involvement in the topic, expressive writing is characterized by subjective use of language, for example descriptive adjectives, neologisms, creative metaphors and collocations as well as unconventional syntax (p.87).

\subsection{Objectives of the Research}

This paper attempts to undertake the task of a stylistic analysis of a sample of E. E. Cummings' (Edward Estlin Cummings, 1962) poetry fairly regarded as representative of Cummings' style in general. The sample consists of two poems. The first is "What If a Much of a Which of a Wind" which belongs to a volume of poetry published in the middle phase of Cummings' evolution: 1x1, published in 1944. This volume reflects the events of early years of the forties and this particular poem raises a controversial question at that time (and ever since) about the results of the atomic war. The second is "anyone lived in a pretty how town" which the researchers have got from 100 Selected Poems by E. E. Cummings, published in 1954 by Publisher Grove in New York. Both poems are available in appendix 1 and appendix 2 .

\subsection{Method of the Research}

The researchers have adopted an analytical discoursed approach that attempts, as much as possible, to make use of statistical analysis of the linguistic characteristics of E. E. Cummings' poetic style as displayed in the two poems under study. 


\section{A Snapshot at Relevant Literature}

\subsection{Early Attempts at Defining Stylistics}

Stylistics is the description and analysis of the variability of linguistic forms in actual language use (Encyclopedia of Linguistics, 2007). It is defined as "the study of literary discourse from a linguistics orientation and is distinguished from literary criticism and linguistics in that it links the two and has no autonomous domain of its own" (Widdowson, H. G., 1975). The prime interest of stylistics is to examine the choice of a given style and its effect on meaning. Therefore, stylistics is concerned with the examination of grammar, lexis, semantics, as well as phonological properties and discursive devices. In other words, it focuses on linguistic choices made by speakers and writers, whether in literary fields or otherwise.

The French classical theory of styles advocated the use of a high (grand) style in all works of literature in contrast to the everyday linguistic discourse, which, according to that school, represented the middle, and low styles. Styles were classified into three major ones. 1) stylus altus (works of art), 2) stylus mediocris (the style of high society) and 3) stylus humilis (the style of low society or comedies). This theory represents early attempts to account for the concept of style as primarily based on the selection of the linguistic means of self-expression (Missikova, 2003).

At the beginning of the 19th century, a German linguist and philosopher, Wilhelm von Humboldt gave an account of different styles in his book "Über die Verschiedenheit des menschlichen Sprachbaues und ihren Einfluss..." and regarded poetry and prose as two opposites. According to him, poetry and prose differ in the selection of expressive devices, such as lexemes, expressions, use of grammatical forms, syntactic structures, and emotional tones, etc. These notions, at the beginning, seemed quite intriguing. Yet, his classification of styles was not really based on or even supported by any linguistic analyses of texts, and, hence, it remained purely theoretical. Later on, however, several linguists went back to Humboldt's classification and elaborated on his ideas. On top of these linguists were the members of the Prague Linguistic Circle (1926), V. Mathesius, B. Havránek and F. Trávníček (Missikova, 2003).

Some literary schools have also contributed towards the development of stylistics. The French school Explication de Texte developed a method of text analysis and interpretation known as close reading. This method was based on a correlation of historical and linguistic information and on seeking connections between aesthetic responses and specific stimuli in the text. The method became quite popular and was used in many other schools and movements.

\subsection{Literary Stylistics}

Literary stylistics is a discipline that links linguistics and literary criticism and makes use of both of them at the same time. The basic goal of literary stylistics is to study and examine thematic and aesthetic values as produced by the choice of certain linguistic forms rather than others in order to convey the creative writer's vision, tone and attitude, (Zhang, p.155). Among the most important landmarks in this respect, indeed, comes Style in Fiction: a Linguistic Introduction to English Fictional Prose by Leech, G. N. and Short M. H. which appeared first in 1981, though the copy used by the researchers is the second edition that was published in 2007. Even though the work takes narrative fiction as its major domain, the contribution of this book to literary stylistics in general can hardly be undermined.

The linguistic forms that attract analysts' attention are usually the fore grounded or deviant ones. Analyzing a text stylistically is unlike doing a "literary" analysis of it; it needs to be much more objectively conducted; it has to be based on textual evidence as manifested in the use of certain linguistic devices employed by the author to convey particular ideas and sentiments as well as produce a certain mental, emotional and psychological effect upon the potential addressee/s, viz. the readers of the literary work in question. It involves the understanding of the concept of style as recurrence of linguistic forms and not simply as a deviation from the norm (Zhang, p.155). Accordingly, this paper aims at indicating how such an analysis is structured, and how to relate linguistic elements to meaning.

\subsection{Stylistics as Deviation}

Deviation is a departure from the norm, which is itself relative and hard to define. Norm can be that of a historical period, of a writer, or even the norm manifested in a text. Nevertheless, a creative writer can sometimes go outside the conventions of a language for special effects. Such deviations are external deviations because the norm is determined outside the text. As Widdowson argues: Literary discourse is characterized by the creation of language patterns over and above those which are required by the linguistic code and these patterns bestow upon the linguistic items within them certain meanings which, when fused with the signification 
these items have as code elements, constitute their unique semantic value in a given context. The application of rhetoric is, indeed, a case in point.

The researchers have chosen E. E. Cummings, as he has radically experimented with form, punctuation, spelling and syntax, abandoning traditional techniques and structures to create a new, highly idiosyncratic means of poetic expression. The meaning of Cummings' work is to be found in the relation between what he is trying to do (his means and techniques) in the one hand and his attitude and vision of life on the other." Particularly in the realms of typography, word usage, rhythm and imagery Cummings is innovator. The reader is immediately struck by Cummings' typography on the first encounter with his poetry. His capitalization (or lack of it), punctuation and line arrangement are immediately arresting. It was Cummings; believing that a poem appearance on the page was especially important in supporting the poet's intention. He wanted and expected his typography to affect the reading of the poem. By this means, he sought to control "the reading rate, emotional evocation and aesthetic inflection so that there might be the smallest possible gap between the actual experience and its expression." (Held, S., 1965)

Cummings' ideas may not be new as such; some are, indeed, quite old. Yet, poetry is an art of making new, of giving new life to the ideas that have always been, the eternal verities; and Cummings set out to refresh his Romantic ideas, and even to renew the very concept of love. His verbal pyrotechnics and typographical eccentricities are products and tools of that artistic quest. By making language look new on the page, he forces his reader to engage the poem at a new level of concentration and, hopefully, to follow that engagement through to the moment of living with which Cummings tried to catch up in the poem. (Blackmur, R. P., 1935)

Cummings' peculiar method of using syntax to convey hidden meaning is extremely effective. The reader does not simply read and forget Cummings' ideas; instead, he/she must figure out the hidden meaning him/herself. In doing this, he/she feels contentment, and thus retains the poem's idea for a more extended period of time. Cummings' ideogram poems are puzzles waiting solved. This type of poetry was a dramatic change to the common poetry people were used to reading. Using this irrational form, E. E. Cummings encouraged people to open their minds to alternative ways of thinking.

Critics have long been puzzled by the simultaneous presence in his poetry of romantic sentiments and experimental typography. Early critics like R. P. Blackmur (1935) often deplored the romanticism (calling it "incorrigibly sentimental") while they ignored or suppressed the typographical "peculiarities." (Robert E. 2008). Thus, E. E. Cummings' (or shall we say E. E. Cummings') poetry may be an ideal topic for stylistic analysis. It is the way in which ideas are expressed and emotions are transformed into linguistic expressions that matters rather than the abstract concept behind them.

\section{First Responses and Critical Views}

In this section of the research, the researchers shall cast a quick look at a specimen of first impressions presented by a sample of general readers as well as a sample of critical views with regard to the two poems in hand. The researchers aim at drawing a comparison and/or a contrast between non-specialist impressions on the one hand and critical views on the other hand, then, eventually, find out how similar or dissimilar both are to the findings of the researchers' stylistic exploration of the two poems in question.

\subsection{First Responses}

The first response to reflect the addressees' feeling of puzzlement on the one hand but also the feeling they have the right to produce their own interpretation freely on the other hand. Various readers have expressed their first reactions to the poem. Following are a few extracts from comments expressing readers' views on the 2 poems in question, as shown on the site of American Poems (Sunday, 8 March, 2009) with regard to "what if a much...." http://www.americanpoems.com/poets/eecummings/756/comments and (Tuesday, 27 March 2012) with respect to" anyone lived ...". http://www.americanpoems.com/poets/eecummings/11880/comments

1) Lyricism and violent images juxtaposed. But the optimist that E. E. Cummings is comes through in the lines-whose hearts are mountains, roots are trees, it's they shall cry hello to the spring. I agree that this is Cummings' reaction to the war when all was turned upside down and the world lost its soul. (Andrea, United States, April 14th, 2009)

2) To me it's rumination-What if everything we believe to be true is actually a lie? And I mean everything like our concept of reality. (Lil Gibson, United States, October 27, 2008)

3) This poem is ultimately about the destruction of the world-a third World War. (Audrey, United States, April 19, 2007) 
4) I really liked this poem because it really showed how "liberal" he really was. If you notice, there are colons, semicolons, and capitalization that are not right. He was really able to express how he did not care what the "rules" were. If that is how he wanted to write it, then why couldn't he. And because of his "liberalness", he is one of the best known writers of history. (Jackie, United States, February 8th, 2006)

5) Okay-so this is my take... E. E. Cummings is totally predicting the future. It's kind of dark and almost pessimistic the first time through but after you read it like 20 times-you see where he was going with it. Lines 9-12 relate back to the secret that is man. The screaming hills aren't hills at all- but a human. (Picture human anatomy for a moment) "strangles valleys by ropes of things" intestines veins, ligaments? Line 15-"whose hearts are mountains; roots are trees- Talking about the strong people who could survive a much of a which of a wind." What if a dawn of a doom of a dream"- that's the beginning of a great and terrible end." and sprinkles nowhere you and me"-when it's all over we will be nothing and belong nowhere. (Megan, September 7, 2005)

6) I read this poem in my college lit class, when told we could write our paper on any poem we read, I chose this one. I fell in love with Cummings as soon as I read this poem. It brought tears to my eyes for several reasons. Not much literature can do that. Now I read as much of his work as I can find. I am glad I still have my book since they took it off this site.... (Robin, United States, March 28, 2012)

7) The poem is good. It reaches many. It is life. It is death. Thank you, Mr. Cummings. (Shannon, United States March 28, 2006)

8) E. E. Cummings presents his views about life and how the individual is able to create more opportunities in life by pushing boundaries than if he were to conform to the demands of society by using sequential diction in an informal sentence structure through a weary tone. The weary tone gives the impression that the narrator has been through many difficult situations and made hard decisions. The tone makes it seem that the narrator has gained quite a bit of experience by living through much of life. With "they sowed their isn't they reaped their same... reaped their sowing and went their came," it gives the audience a feeling that the people have been working and gaining experience for a long time. In reality, the sowing and reaping process of crops takes an entire year. The narrator alludes to this fact with the "anyone" and "no one" sowing and reaping to show that they have been through hardships together and for a long time that in fact extends towards many years. Much of this is derived from the aphorism, "one reaps what they sow". The tone emphasizes the belief that one should be able to make their own decisions; they should be able to live their life just as they like it. (Emily, United States, February 25, 2006)

9) What is with everyone capitalizing E. E.! Do you know nothing about the man? He didn't capitalize anything, so please make it E. E. Cummings! (Brit, Canada, March 2nd, 2006)

10) I think that these is you best poem that I have ever read in my whole life. I think that you are good poet and you have a lot to look forwards too. (Emily, United States, February 27, 2006)

\subsection{Critical Views}

Leaving the general readers' impressions and immediate responses aside and exploring more technically informed views does not lead us, however, to a very different area. Much of the general impressions displayed in the comments of the general readers are to be found in the criticism written by experts on the subject of poetry.

As Stickney, Margaret Mary (1985) puts it in her MA thesis, "many critics have failed to take Cummings seriously" (p.9) because they get the impression that Cummings is chiefly one who scatters words somewhat barbarously over a page in a rebellious fashioning of his own typography.

In her PhD thesis (2010), Kathrin Khalil Bajis Maali asserts that Cummings has even moved from simply being a modern poet into a post-modern one, with many poems of his that have a certain "unique and exquisite style which distinguishes them from the traditional poem". Maali refers to his transition from the writing of traditional sonnets and poetry that meets the classical requirements of style into "writing poetry that defied the rules of grammar, style, punctuation and ideals of the modern era and the traditional poem" (Ibid).

The two poems at hand may be seen as typical examples of the above-cited views of a few critics. Yet, in fact, the very poems can be fairly taken as an affirmation of a recurrent theme in Cummings' poetry: an affirmation of the indestructibility of man. Nature-as in many of Cummings' poems-is brought into the scene. The bomb is likened to a wind, which blows everything away, even the skies and the oceans. Only Man, being the only secret of nature, will remain constant. Cummings goes on hypothesizing that if a bomb destroys the universe, blowing "me and you" to "nowhere", only those individuals who had had a firm close relationship with nature will "cry hello to the spring" (Held, S., 1965). 
According to Theo Steinmann (1978), in his poem "Anyone Lived in a Pretty How Town", E. E. Cummings "cumulates different kinds and levels of rhythm in order to suggest the complexity of superimposed sensuous and mental impressions." The most striking pattern is represented in the revolution of the seasons, as indicated by the rotating list of their names. With each of the abstract terms the poet associates a natural phenomenon characterizing the particular season on the sensuous level of human experience so that one may stand emblematically for the other: sun-summer; moon-autumn; stars-winter; rain-spring.

Cummings' "technical innovations are many and spectacular. Not anarchistic flaunting of sense, they are best understood as various ways of stripping the film of familiarity from language in order to strip the film of familiarity from the world. Transform the word, he seems to have felt, and you are on the way to transforming the world" (Biography of E. E. Cummings).

\section{A Stylistic Exploration of E. E. Cummings' Poems "What if a Much of a Which" and "Anyone Lived in a Pretty How Town"}

We may see from the comments of unspecialized readers as well as critics that the poems are quite open to different interpretations. Those interpretations range from the description of the "What if a Much of a Which" as a depiction of the destruction of the whole world to the reference to Cummings as an optimist and then as pessimist, while one comment saw the poem mainly as an expression of the liberal mentality and attitudes of E. E. Cummings. On the other hand, the same comment, number 7 states "it (the poem) is life. It is death" both at the same time. Comment number 8 even attempted a real critical appreciation, depending on referring her analyses back to textual evidence rather than simply attempting an impressionistic interpretation. Another one, number 10, went further still, modeling her own comments on the deviational style of Cummings himself! The one thing that all readers, critics as well as non-specialists, would not find difficult to pin down is the clearly different style of writing of the two poems. The question is how the text yields itself to such a variety of different, if not even, sometimes at least, contradictory, views. This is where stylistic comes in.

The researchers shall attempt to depict the lexical and syntactic components of the two poems in question to come up with an overall picture of Cummings' stylistic features resulting from the use of particular lexemes and/or syntactic structures. In the light of this analysis, one can see how far the initial responses to the poems have or have not stemmed from the very nature of the work as such.

\subsection{Lexical Features}

To start with, a quick look at the class of open words or content words may prove useful. Open class words to "which an independent meaning can be assigned" (WordWeb, 2007) may be opposed to closed class (grammatical) words such as determiners (e.g. this, that, the) and prepositions (e.g. in, at, on). Closed class words act like sentence "glue" and link together open class words in meaningful arrangements (sentences). Table 1 shows how the open class words are distributed throughout the poem "What if a Much of a Which", and whether they are nouns, verbs, adjectives or adverbs, while table 3 shows the same with respect to the poem "Anyone Lived in a Pretty How Town".

Table 1. Distribution of open class words

\begin{tabular}{cccc}
\hline Nouns & Nouns & Adjectives & Main Verbs \\
\hline Abstract & Concrete & Attributive & Action Verbs \\
\hline Truth-Lie & Wind-Leaves & Dizzying & Give \\
Hope-Terror & Stars-king & Lean & Bloodies \\
Seeing-Blind & Beggar-Queen & screaming & Yank \\
Pity-Envy & Friend-Fiend & Immortal & Blow \\
Spring-Dawn & Skies-Oceans & Single & Strangles \\
Doom-Dream & Man-Sleet & Hugest & Stifles \\
Life-Death & Hills-Snow & Keen & Cry \\
Space-Time & Valleys-Ropes & White & Bite \\
Soul-Mind & Things-Forests & & Peels \\
Hearts-Universe & Mountains-Roots & & Sprinkles \\
Secret-Much* & Trees-Home & & Blow \\
Which*-Seem* & & 8 & \\
\hline 24 & 22 & & 11 \\
\hline Total & 65 & & \\
\hline
\end{tabular}


It can be seen from table 1 that the total number of open class words or content words is 62 out of 173 (the total number of words in the poem). Thus, the number of functional words exceeds the number of content words that are usually supposed to carry the message of any discourse. In this poem, however, the message lies in the unconventional use of functional words. Besides, some of these functional words are actually used in the poem as if they were content words (marked in table 1 with an asterisk). A case in point is "which" preceded by the determiner "a" in the recurrent phrase "What if a Much of a Which". In fact, even "much", which is strictly speaking an adjective, is also used as a noun here.

Table 2 on the other hand, shows the total number of class words or content words as 73 used 87 times out of 228 lexical items all together. In this poem too, some verbs are used as nouns (marked with an asterisk in the table), and both content and functional words seem to fuse together and, thus, help convey the message of the poem. In both cases, the message of each of the two poems is not simply an idea to convey to the addressee, but rather a comprehensive feeling, impression and a state of the mind, all of which provide the addressee with open possibilities for different interpretations of one and the same poem. The poet is not out to lecture us about the destruction of nature or preach to us about the precious value of humanity as such. In his rebellion against the conventional and traditional, E. E. Cummings recreates his own rebellious experience on paper on all levels; the lexical, the syntactic, phonological and even graphological.

Table 2. Distribution of open class words

\begin{tabular}{cccc}
\hline Nouns & Nouns & Adjectives & Main Verbs \\
\hline Abstract & Concrete & Attributive & Action Verbs \\
\hline Hope & Children & Pretty & Lived- Cared \\
Sleep & Eyes & Floating (2) & Sang- Danced \\
Dream & Women & Many (2) & Sowed- Reaped (2) \\
Spring (3) & Men & Deep & Guessed- Forgot \\
Summer (3) & Face & Still & Grew- Loved \\
Autumn (3) & Folk & Little & Laughed- Cried \\
Winter (3) & Tree & Small & Married- Did \\
Spirit & Leaf & Busy & Sleep- Wake \\
Joy & Bird & How* & Hope- Said \\
April & Snow & Ding* & Slept- Begin \\
Day & Everyones* & Dong* & Explain- Forget \\
Wish & Noone* & & Remember- Died \\
Didn't* & Anyone* $(5)$ & & Guess- Stooped \\
Did* & Cryings* & & Kiss- Buried \\
Same* & & & Dream- Earth \\
Nevers* & & & \\
Came* & & & \\
Sowing & & & \\
\hline 18 Nouns & 11 Nouns & & \\
26 Times & 18 Times & & \\
\hline Total & Content Words & & \\
\hline
\end{tabular}

As indicated in the above two tables, table 1 and table 2, open class words consist mainly of nouns and verbs. The concrete nouns, i.e., words that refer to physical objects, can be divided further into two rough areas of meaning, or semantic fields. Tables 3 and 4 show how this might be done: lexemes related to nature versus other ones that are related to humans. The mixture in the poem of nouns belonging to these two different semantic classes could be said to account for what we perceive as an interconnection between nature and man. Some of the abstract nouns mentioned in table 1 could belong to either category and might be seen to connect the two semantic classes together.

The number of abstract nouns is quite close to almost that of concrete nouns in both poems: 21 to 22 in "What of a Much of a Which" and 18 to 14 in "Anyone Lived in a Pretty How Town". This may echo some kind of balance or even dialectic between the ideal and the empirical or between the down-to-earth and the sublime. Another balance or dialectic in the two poems may also be detected between nature, on the one hand, and man on the other hand as shown in tables 3 and 4. 
Table 3. Distribution of nouns within 2 basic semantic classes

\begin{tabular}{cc}
\hline Nouns Related to Nature & Nouns Related to Humans \\
\hline $\begin{array}{c}\text { Wind, Leaves, Stars, Skies, Oceans, Hills, Snow, } \\
\text { Valleys, Forests, Mountains, Roots, Trees }\end{array}$ & King, Beggar, Queen, Friend, Fiend, Ropes, \\
\hline Total $=12$ & Things, Man, Home. \\
\hline
\end{tabular}

In table 3, ("What If a Much ..."), we see that 12 nouns are related to nature while 9 are related to man per se. In table 4, ("Anyone Lived in a Pretty ..."), 11 nouns are related to nature while only 8 are related to man, with almost the same percentage of occurrence in table 3. To start with, the numbers are close in both cases, may be again indicating some kind of balance or dialectic. Second, almost all the words that are related to nature in the first poem occur in the plural form (10 out of 12), while those related to man are mainly not (2 out of 8). Yet in the second poem, which seems to focus on the common man or anti-hero figure, most nouns that are related to man occur in the plural form (5 out of 8) while those related to nature are not ( 1 out of 11). This may represent the oneness of nature despite its plurality as opposed to the individuality of man even though man is ultimately responsible for the possible destruction of the world he lives in.

Table 4. Distribution of nouns within 2 basic semantic classes

\begin{tabular}{|c|c|c|}
\hline \multicolumn{2}{|r|}{ Nouns Related to Nature } & \multirow{2}{*}{$\begin{array}{c}\text { Nouns Related to Humans } \\
\text { Children }\end{array}$} \\
\hline & Tree & \\
\hline & Leaf & Eyes \\
\hline & Snow (2) & Everyones \\
\hline & Sun (3) & Noone \\
\hline & Stars (3) & Anyone \\
\hline & Rain (3) & Women \\
\hline & Moon (3) & Men \\
\hline & Spring (3) & Face \\
\hline \multicolumn{3}{|c|}{ Summer (3) } \\
\hline \multicolumn{3}{|c|}{ Autumn (3) } \\
\hline \multicolumn{3}{|c|}{ Winter $(3$} \\
\hline Total & 11 & 8 \\
\hline & 28 Times & \\
\hline
\end{tabular}

The use of words related to nature in the plural form in the first poem can also reinforce the impression that "everything can be affected in nature except Man". The use of the plural form in this case may emphasize the idea that multiplicity may indicate and entail diversity, potential weakness and fragility, whereas singularity can be more associated with individuality, genuineness and hence Man. At the same time, the use of plurality in the second poem may reflect individuality, diversity and multiplicity in relation to the common men and anti-heroes. Even though Man is the focus of the second poem, it is the down-trodden street men that come and go unnoticed and hardly sympathized with. The same technique and/or lexical, semantic or grammatical feature can be used by Cummings to produce various if not even contradictory effects in different contexts, which, in turn, helps create the same kind of balance or dialectic above mentioned.

As for the use of verbs in the two poems in question, most of them are verbs of action. There are eleven uses in the first poem and 28 uses in the second poem, with a total of 39 versus only two occurrences of sativa verbs in "Anyone Lived in a Pretty How Town" and one occurrence of verb "seem" in "What if a Much of a Which ...". Though used as a noun, it occurs in the NP position of an indirect object: "Blow king to beggar and queen to seem". With the exception of linkage verbs in different forms and tenses such as "is" and "was" in both poems, the dominance of action verbs may help reinforce the hypothetical nature of the two poems and the idea that nothing is certain and that everything may cease to be what it seems to us now. In other words, anything and everything is open to different interpretations.

If we now look at the verbs in the poem, we can see that they create a sense of immediacy as we read it. All the verbs that are marked for tense (finite verbs) are in the present tense. Therefore, we have present simple verbs such as "gives" [2], "yanks" [4] and "strangles" [11]. 
The use of pronouns instead of nouns in "What if a Much of a Which ..." as well as the use of pronouns as if they were proper nouns such as "anyone" and "noone" in "Anyone Lived..." may also help make poems not only more open to different interpretations but also less tied down to concrete individual entities. Since concrete and/or abstract nouns are by definition more specific than pronouns. At least, any noun must have one or even a few definite denotations, whereas pronouns, by definition, are used to substitute and or replace any noun whether concrete or abstract and regardless of its/their denotative meanings, let alone associations and connotations.

\subsection{Grammatical Features}

Cummings combines repetition of deviation with a cohesive function in pattering that secures the unity of his poems. The syntactic level of his poems is often a persuasive parallelism based on syntactic deviation. (Kidder, R. M., 1979)

The first poem consists of three stanzas, with strictly speaking three complex sentences only, one in each stanza. All the main clauses are in the interrogative, starting with the WH question word "What", which enforces the hypothetical nature of the poem as well as invites the addressee to act as part of the poetic creation of the poem by providing a possible answer. Every first two lines in each stanza are interrogative but the question mark only appears after the fourth line, with a continuation of the second part of the question. While the fifth and sixth lines are also a continuation of the second part of the original question but start with a capital letter. It may be in order to indicate the significance attached to the semantic content of that part of the extended question "Blow king to beggar and queen to seem", "Blow hope to terror; blow seeing to blind" and, finally, "Blow soon to never and never to twice". Each line is followed by a bracketed alternative suggesting another face of the same coin. All of them concentrate on the consequences of the hypothetical question, and there is a complete reversal of order on all levels: friend is blown into a fiend (human); space to time (nature); pity to envy (emotional); soul to mind (mental and spiritual); and eventually life to nothingness (isn't), where you would have expected "death" and "death" simply to the past, the no longer existent "was".

Only the last two lines in each stanza are not in the interrogative, with fifth lines in the first two stanzas starting with a relative pronoun that could also be used in other contexts as a question word: "when" and "whose". The fifth line in each of the 3 stanzas, however, does not mark the beginning of a new sentence; it always comes after a dash, not a full stop. This may help emphasize the continual nature of the whole process of destruction depicted in Cummings' poem.

The main theme is the confusion of appearance and reality, nothing is what it seems, and, furthermore, everything is its own counterpart. Pronouns (relative or not) replace nouns, the king could become a beggar and the queen is only a pseudo-queen ("Seem" here is used as a noun, yet it could also be interpreted as a lexeme that marks the beginning of a new incomplete clause to the effect: only seems a queen but is not really one). The poem is also an open world of possibilities: everything is both "is" and "was" and everything could be everything else. All possibilities and probabilities are valid. This world is not as stable and systematic as it may seem to us. You and I are part and parcel of this "plan-less plan" of our world. The use of pronouns instead of nouns makes the poem more open to different interpretations and less tied down to concrete individual entities.

The second poem "Anyone Lived in a Pretty How Town" is also a typical example of Cummings' use of syntactic and grammatical deviation in his poetry even though in a rather different way this time. It consists of nine stanzas with 36 lines, each stanza made up of 4 lines. As Yu Xueyong (2011) puts it, "Its plot is simple but hard to understand, and its success lies in exquisite language" (chapter 9). The use of antonymous verbs in pairs of clauses with the second used as a verbal noun in the form of a gerund or even treated as a noun while retaining its verbal tense form. "Laughed their cryings" and "reaped their sowing" are examples of the former, while "he sang his didn't", "they sowed their isn't" and "and went their came" are cases in point of the latter.

In both poems, Cummings tries to capture the idea of a multitude of thoughts occurring simultaneously by breaking grammatical conventions. He uses both definite and indefinite references within the same clause (a much, a which)."Which" is a relative pronoun that is supposed to refer to something definite, however, it is used with an indefinite article "a" an indefinite article. The same applies to "a much": much is a "quantifier used with mass nouns" (WordWeb Pro, 2007), and hence, not normally used with indefinite articles as if it were a noun. Similarly, "never" becomes "nevers" and instead of dreaming while sleeping the "folk" "slept their dream"! This may enhance the possibility that anything and everything could happen as well as the notion of uncertainty and chaos.

\subsection{Phonetic and Phonological Features}

The use of alliteration and assonance is characteristic of Cummings' poetry. The two poems under study are 
certainly no exception of that feature. Similar sounds yield themselves to each other, with the whispering voiceless $/ \mathrm{s} /$ and /f/ on the one hand, and the noisy explosive voiced semi-vowel $/ \mathrm{w} /$ and bilabial $/ \mathrm{b} /$ on the other hand dominating most of the poem. The /w/ occurs 12 times in initial position. The first three successive $/ \mathrm{w} / \mathrm{s}$ occur in the question word "what" in the first line. The relative pronoun used as a concrete noun "which" and the "wind" that blows everything to its opposite, while the last occurrence is in the very last line, maybe marking the presence of the other side of the equation. The reason for the destruction of nature and, paradoxically, the only one that can stop it, survive it, and produce life out of death, viz. man.

Another instance of parallelism in the poem occurs at the phonological level, where the rhyme scheme is irregular except that of the second and fourth lines of every stanza rhyme. Cummings does make use of internal rhyme at particular points within the poem. There is no strict pattern to its occurrence, yet, there is some degree of phonological parallelism in each stanza, such as the repetition of vowel sounds in words in close proximity to each other.

\subsection{Deviation and Parallelism}

Perhaps the most striking aspect of deviation in the two poems is the almost constant use of lower case letters where we would normally expect capitals. This, though, is typical of Cummings' poetry and so one may not attach much significance to it with regard to these two poems under study, except, perhaps, where Cummings' desire to break with normal conventions comes in. However, one of the effects of this graphological deviation is to foreground any instances where Cummings does use capitalization. Consequently, one may infer that the word 'Blow' in the 5th line of every stanza in the first poem ("What if a Much of a Wind") highlights an important theme-viz. the destruction of everything except man- in the poem, since it is the first word the reader would come across with initial capitalization. Likewise, only the two occurrences of the word "Women" in the phrase "Women and men" in the second poem, "Anyone Lived in a Pretty How Town", are capitalized to contrast them with "anyone" and "noone" who love each other but are downtrodden and marginalized. Women and men, on the other hand, lead the society and conform to its conventions, no matter whether they are "both little and small" or "both dong and ding", and no matter whether these conventions are social such as marriage or simply graphological such as the capitalization of the first letter in a written sentence.

In addition to the graphic deviations, there are also a number of grammatical deviations in the two poems. Many of these occur due to Cummings' tendency to use punctuation where it would not normally be necessary. For instance, we get phrases being bracketed which may be used to indicate visually immediacy or simultaneously. Examples may be found in the sixth line of every stanza in the first poem starting with "blow" and the bracketed "both" phrases in the second poem "both little and small" and "both dong and ding". Again, this contributes to our understanding of the poem as being very active and dynamic and emphasizes the idea that everything would be destroyed except Man.

If we examine the poems closely, we can see that there is actually some kind of systematicity to grammatical deviations. In other words, there is order bestowed on chaos and systematization of the breaking of systems! Following are a few examples from both poems:

1) Every stanza in "what if a much ..." starts with a rhetorical question-made up of four lines-such as the following example in the first stanza

what if a much of a which of a wind

gives the truth to summer's lie;

bloodies with dizzying leaves the sun

and yanks immortal stars awry?

2) Every fifth line in each stanza of the same poem starts with verb "Blow" with an initial capital letter

3) Line six in every stanza is written between brackets.

4) Line seven in every stanza begins with a hyphen that may be used to slow down the tempo or to foreground a specific line.

5) In "Anyone Lived in a Pretty How Town", only the fourth and eighth stanzas are devoid of bracketed sentences or phrases.

6) The use of bracketing starts with a whole line in the first stanza, then a short phrase forming only part of a line in the second stanza and finally a much longer bracketed sentence along three different lines with the third stanza. The fourth stanza has no bracketed clauses and/or phrases at all. Then, with the fifth stanza, the whole process 
isrepeated but upside down. First, the longer bracketed sentence along three different lines, then the short phrase forming only part of a line and, finally, a whole bracketed line.

7) The above-mentioned use of bracketed phrases and or clauses reflects the same circular revolution of the seasons with relevant natural phenomena or objects in the poem. Thus, we first have "spring summer autumn winter" corresponding to "sun moon stars rain" in the first stanza, but in the last stanza, we have "summer autumn winter spring" corresponding to "sun moon stars rain". The change of order may again reflect the revolving nature of the universe as a whole. Disorder is embedded in order and order is yet an innate feature of disorder. Form and content both interact to give birth to a work of art that is almost as open to different interpretation as life itself.

Thus, we may conclude that E. E. Cummings is systematic in his grammatical deviations which may, in turn, underline the idea that there is still some kind of order amid this chaotic world or may be to illustrate the idea that although everything is uncertain, there is only one certainty which is "nothing is certain".

In addition to the graphological deviation in the poems, there is also some degree of graphological parallelism in the arrangement of the poems into stanzas. The first poem is set up in 3 regular eight-line stanzas. This seems to suggest that there is some order in form of the poem. It is not the chaotic graphological jumble that it first appears. It is difficult, though, to know what to make of the parallel structure of the poem, and if we were to try to relate it to our initial impression of the poem, it would be a pretty tenuous interpretation. However, Dixit (1977) studied a corpus of E. E. Cummings poems in detail and concluded that, far from being arbitrary examples of deviation, the poems are, in fact, systematically deviant.

\section{Conclusion}

Having analyzed the two poems in question stylistically, making use of a more or less a statistical approach, the researchers may be entitled to reflect on whether or not the initial responses to the poems as well as the critical reviews are compatible with the findings of the statistical analysis.

The analysis proves that the poems are open to several possibilities and interpretations, which is, in turn, reflected in the use of pronouns instead of nouns, the excessive use of functional words as well as the seemingly deviant stylistic techniques, in addition to the use of verbs and relative pronouns or question words as if they were nouns. The boundaries between different lexical and grammatical categories seem to fade away, just like man and Nature at times seem to intermingle and become one, while at other times they appear to stand in contrast with each other. Everything is a may be.Everything is possible and everything may turn to be something else or nothing at all. Yet, on the other hand, there is some kind of consistency in the use of "deviant techniques" throughout the two poems, if not even through most of Cummings' poetical works. Life and death are two sides of the same coin, death leads to growth, to life, and life ends with death. Order manifests itself within disorder and symmetry is born from chaos. However, the consistency in using these so-called "deviant techniques" may be fairly regarded as compatible with a few of the first responses of non-professional readers that may be summed up as follows:

\section{1 - There is always order amid chaos or,}

2- That humanity will survive despite the destruction of everything.

The previous analysis of E. E. Cummings' poems shows how one can make use of stylistics to uphold an interpretation of a poem, and how stylistics can also highlight elements of a poem that one might otherwise miss. It also enables us to speculate with more certainty on precisely why E. E. Cummings may have chosen to use such seemingly odd stylistic techniques. For example, we see that deviant punctuation is linked to the foregrounding of dynamic verbs, explaining why we perceive that there is much 'movement' in the two poems under study.

Analyzing the poems stylistically also highlights how the most internally deviant features of a given poem may be the very same ones which we would usually consider 'normal', non-deviant language in both everyday communication and within poetry, and suggests a reason as to why this might be the case. Stylistics, then, is helpful in explaining parts and aspects of a text that might otherwise skip the attention of the reader.

In conclusion, though, this research has only attempted to cast some light on how the linguistic features of a poem are directly related to the conceptual message of the literary work, and, in doing so, the researchers have upheld their initial interpretation of the poems under study. Indeed, the interpretation endorsed by the researchers is not the only one that could be given to the poems. However, by using a systematic analytical technique like stylistics, one can, at least, ensure that a given interpretation is as explicit, objective and grounded in facts as it can be. It is also highly likely that any other stylistic analysis of the poems concerned would include, at least, 
some of the main findings or even conclusions of the present research. The researchers hope, then, that they have illustrated how to explain why a text makes one feel in a particular way rather than another, and that this research has gone some way towards convincing the reader that stylistics is a useful tool for anybody interpreting literary texts, not only the professional critic, but also the non-specialist reader.

\section{References}

Antony, L. (2007). Electronic Dictionaries and Encyclopedias (CD ed.), Encyclopedia of Linguistics, Alphabet-S Chapter 49: STYLISTICS.

Ball State. His Students, (pp. 105-111). Cambridge, Mass: Slavica Publishers.

Biography of E. E. Cummings. Retrieved 27 March, 2012, from http://www.americanpoems.com/poets/eecummings/756/comments

Blackmur, R. P. (1935), The Double Agent. Retrieved from http://www.enotes.com/poetry-cummings-salem/poetry-cummings

Dixit, R. (1977). Patterns of Deviation in Selected Poems of E. E. Cummings, (Unpublished M. A. Dissertation). Lancaster University.

E. E. Cummings, Anyone Lived in a Pretty How Town. Retrieved from http://litmed.med.nyu.edu/Annotation?action=view\&annid=809

E. E. Cummings. (2007). 100 Selected Poems, English Fictional Prose (2nd ed.). London: Longman. Edition Copyright 1923-1954.

E. E. Cummings. What If a Much of a Which of a Wind. Retrieved from http://www.poemhunter.com/

Fairley, Irene R. (1975). E. E. Cummings and Ungrammar: a Study of Syntactic. Michigan University: Watermill Publishers.

Friedman, Norman. (1972). E. E. Cummings: A Collection of Critical Essays. California: Prentice-Hall.

Gribble, Charles E. (Ed.). (1968). Syntax as Style: An Analysis of Three Grove. Slavica Publishers.

Held, Sharo. (1965). E. E. Cummings: Theme and Development. http://www.americanpoems.com/poets/eecummings/11880/comments

Kidder, R. M. (1979). E. E. Cummings: An Introduction to the Poetry. Konštantína Filozofa: Nitra University.

Leech, G. N., Short, M., \& Short, Michael H. (1981). Style in Fiction: a Linguistic Introduction to English Fictional Prose. Michigan University: Longman.

Lipski, John M. (1975). Connectedness in Poetry: Toward a Topological.

Maali, Kathrin Khalil Bajis. (2010). E. E. Cummings: A Postmodernist Approach (Unpublished Master Thesis). Library- Center of Thesis Deposit. University of Jordan.

Mikissova, Gabriela. (2003). Linguistic Stylistics. New York: Columbia University Press.

Reiss, Katharina. (1977). Text Types. In Chesterman, A. (Ed.), Translation Types and Translation Assessment (p. 87).

Robert, E. (1965). The Poetry and Prose of E. E. Cummings. Harcourt, Brace \& World.

Steinmann, Theo. (1978) Semantic Rhythm in 'Anyone Lived In A Pretty How Town' Concerning Poetry, 11, 71-73. Retrieved from http://www.english.illinois.edu/maps/poets/a_f/cummings/howtown.htm

Stickney, M. M. (1985). Home at heart: The Experimental Use of Language in the Poetry of Gerard Manley Hopkins and E.E. Cummings. Retrieved from http://digitalcommons.mcmaster.ca/opendissertations/5896/

Studies Presented to Professor Roman Jakobson by Deviances in His Poems. New York: Watermill Publishers.

Wegner, Robert E. (1965). The Poetry and Prose of E. E. Cummings. Harcourt, Brace \& World. Retrieved Nov. 23, 2008, from http://www.enotes.com/poetry-cummings-salem/poetry-cummings

Widdowson, H. G. (1975). Stylistics and the Teaching of Literature. London: Longman.

Xueyong, Yu. Appreciation of E. E. Cumming's Poetry-From the Perspective of Foregrounding [MS Wordform]. Retrieved Dec. 28, 2011, from http://jpkc.hdu.edu.cn/foreignedu/ymwx/jxkj/

Zhiqin, Zhang. (Ed.). The Interpretation of a Novel by Hemingway in Terms of Literary Stylistics. The International Journal of Language Society and Culture. Retrieved from 
http://www.educ.utas.edu.au/users/tle/JOURNAL/

\section{Appendix}

Appendix 1

what If a much of a which of a wind

E. E. Cummings

what if a much of a which of a wind

gives the truth to summer's lie;

bloodies with dizzying leaves the sun

and yanks immortal stars awry?

Blow king to beggar and queen to seem

(blow friend to fiend: blow space to time)

-when skies are hanged and oceans drowned,

the single secret will still be man

what if a keen of a lean wind flays

screaming hills with sleet and snow:

strangles valleys by ropes of things

and stifles forests in white ago?

Blow hope to terror; blow seeing to blind

(blow pity to envy and soul to mind)

-whose hearts are mountains, roots are trees,

It's they shall cry hello to the spring

what if a dawn of a doom of a dream

Bites this universe in two,

peels forever out of his grave

and sprinkles nowhere with me and you?

Blow soon to never and never to twice

(blow life to isn't: blow death to was)

-all nothing's only our hugest home;

the most who die, the more we live.

Appendix 2

anyone lived in a pretty how town

E. E. Cummings

anyone lived in a pretty how town

(with up so floating many bells down)

spring summer autumn winter

he sang his didn't he danced his did

Women and men (both little and small)

cared for anyone not at all 
they sowed their isn't they reaped their same

sun moon stars rain

children guessed (but only a few

and down they forgot as up they grew

autumn winter spring summer)

that noone loved him more by more

when by now and tree by leaf

she laughed his joy she cried his grief

bird by snow and stir by still

anyone's any was all to her

someones married their everyones

laughed their cryings and did their dance

(sleep wake hope and then)they

said their nevers they slept their dream

stars rain sun moon

(and only the snow can begin to explain

how children are apt to forget to remember

with up so floating many bells down)

one day anyone died i guess

(and noone stooped to kiss his face)

busy folk buried them side by side

little by little and was by was

all by all and deep by deep

and more by more they dream their sleep

noone and anyone earth by april

wish by spirit and if by yes.

Women and men (both dong and ding)

summer autumn winter spring

reaped their sowing and went their came

sun moon stars rain 